\title{
Performance of a 2-Megawatt High Voltage Test Load
}

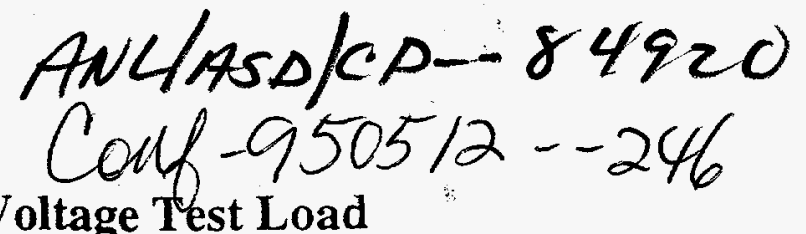

\author{
D. Horan, R. Kustom, M. Ferguson \\ Advanced Photon Source, Argonne National Laboratory \\ 9700 South Cass Avenue, Argonne, Illinois 60439
}

\section{Abstract}

A high-power, water-cooled resistive load which simulates the electrical load characteristics of a high-power klystron, capable of 2 megawatts dissipation at $95 \mathrm{kV} \mathrm{DC}$, was built and installed at the Advanced Photon Source for use in load-testing high voltage power supplies. During this testing, the test load has logged approximately 35 hours of operation at power levels in excess of one megawatt. Slight variations in the resistance of the load during operation indicate that leakage currents in the cooling water may be a significant factor affecting the performance of the load. Sufficient performance data have been collected to indicate that leakage current through the deionized (DI) water coolant shunts roughly 15 percent of the full-load current around the load resistor elements. The leakage current could cause deterioration of internal components of the load. The load pressure vessel was disassembled and inspected internally for any signs of significant wear and distress. Results of this inspection and possible modifications for improved performance will be discussed.

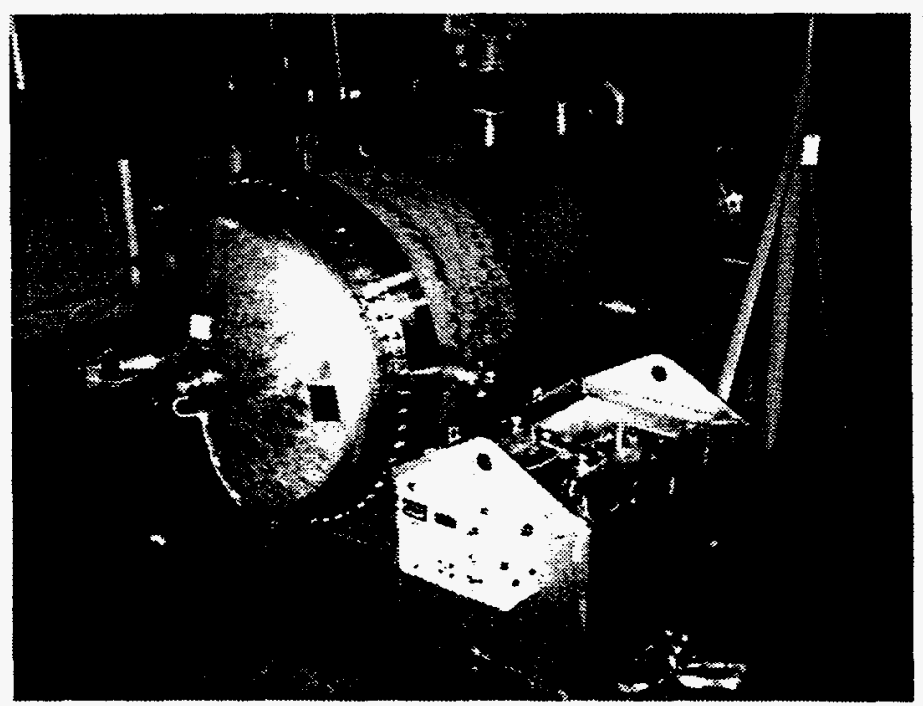

Figure 1: Overview of load system.

\section{INTRODLCTION}

A high-power water-cooled resistive load, capable of 2 $\mathrm{MW}$ at $95 \mathrm{kV} \mathrm{DC}$, was designed and built at the Advanced Photon Source specifically to be used as a test load for the if power supplies. The load simulates the filament, mod-anode, and cathode load characteristics of the Thomson TH-2089A

* Work supported by the U.S. Department of Energy. Office of Basic Energy Sciences, under Contract Yo. W-31-109-ENG-38. klystron [1], and allows for more convenient maintenance and testing of the power supply units. The load consists of two sub-assemblies, connected to each other by a high-voltage coaxial cable of sufficient length to reach all five APS if power supplies (see Fig. 1). The resistive filament and mod-anode loads are contained within a portable oil-filled tank which can be wheeled into position next to the power supply to be tested. High-voltage connections between the power supply and the load system are made using connectors on the oil tank which are identical to the ones used on the klystron, therefore making connection to a power supply system convenient. The highpower portion of the load is a pressure vessel which contains wire-wound resistor elements cooled by a continuous flow of DI water (see Fig. 2). This vessel is connected to the oil tank by a 350 -foot coaxial high-voltage cable, allowing the load system to reach all five if power supplies. Construction of the load assemblies was completed in January 1994, and the load was used successfully for initial testing of all five APS if power supplies. These tests involved checking cathode and mod-anode voltage regulation performance, ripple content, heater supply current regulation, and high-power heat runs. The final power supply was tested on November 18, 1994, resulting in a total of approximately 35 hours of load use at power levels of one megawatt or greater. At the conclusion of this testing activity, the high-power dissipation portion of the load was disassembled and inspected for signs of distress.

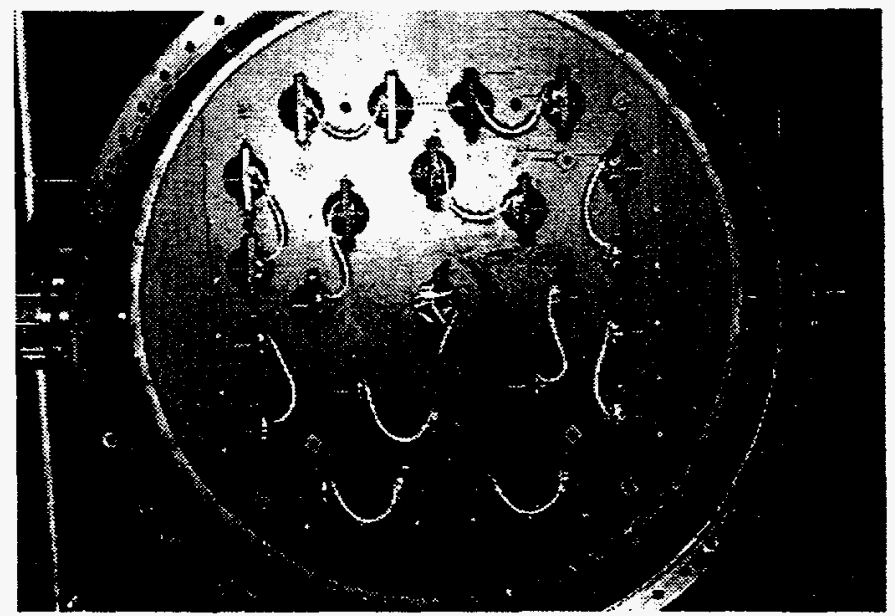

Figure 2: Internal view of pressure vessel with resistor assemblies.

\section{PERFORMANCE DATA}

At initial assembly, the 100 series-connected wirewound resistor elements in the pressure vessel (see Fig. 3) were measured at room temperature and found to have a total resistance

$$
\begin{aligned}
& \text { The submitted manuscriot has been authored } \\
& \text { by a contractor of the U.S. Government } \\
& \text { under contraci No. W-31-109-ENG-38. } \\
& \text { Accordingiv, the U. S. Government retains a } \\
& \text { nonexclusive, royalty-tree license to publish } \\
& \text { or reproduce the published form of this }
\end{aligned}
$$




\section{DISCLAIMER}

Portions of this document may be illegible in electronic image products. Images are produced from the best available original document. 
of $4360 \mathrm{ohms}$. This resistance was expected to increase to approximately 4750 ohms at operating temperature due to the positive temperature coefficient of the resistor wire material. When operating at a calibrated output voltage, the load current values indicated that roughly 15 percent of the full-load current was shunted around the load resistor elements through the cooling water. This necessitated limiting the maximum test voltage on the load to $65 \mathrm{kV}$, as the power supply is designed to current-limit at 20 A output. Also, while operating at $60 \mathrm{kV}$ and above, there were occasional sudden variations in load current, possibly indicating the presence of arcing or breakdown phenomenon somewhere in the pressure vessel. This instability was subtle and intermittent in nature and was not considered a serious threat to the operation of the load. The oil tank and interlock systems of the load performed without problem. The load system was used successfully to complete the initial high-power tests on all five APS rf power supplies.

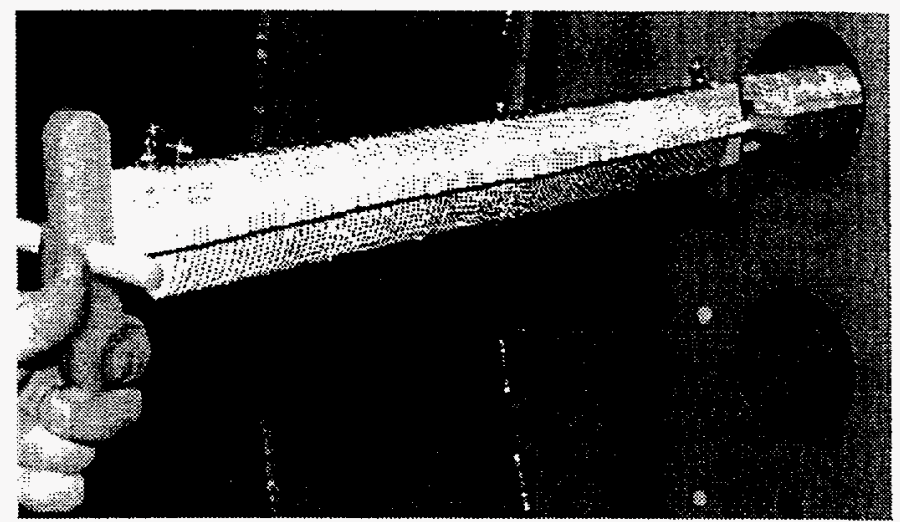

Figure 3: Photograph of resistor element

\section{INTERIOR INSPECTION}

After completion of the power supply testing, the pressure vessel was disassembled and inspected for evidence of distress. Attention was paid to evidence of corrosion, electrolysis, electrical breakdown, and overheating of interior structures.

Evidence of electrical breakdown or deterioration was noted in two places within the vessel: in the high-voltage silicone lead wire used to connect the input cable termination to the resistor string, and on oneof the tubes containing the resistors. The wire deterioration was most likely caused by the cable moving about in the turbulent water and passing too close to the interior surface of the vessel end bell since it is necessary to leave some slack in this wire to assemble the high-voltage cable termination to the end bell. The breakdown of the resistor-containing tube (see Fig. 4) was caused by using a material with lower grade electrical properties than the tubing material used elsewhere in the load.

Two varieties of G-11 tubing were supplied by the vendor, visually differing only in color-one tan and the other traditional green. Both types were certified by the manufacturer to have the same electrical properties. However, subsequent hipot tests on samples indicated that the tan tubing suffered

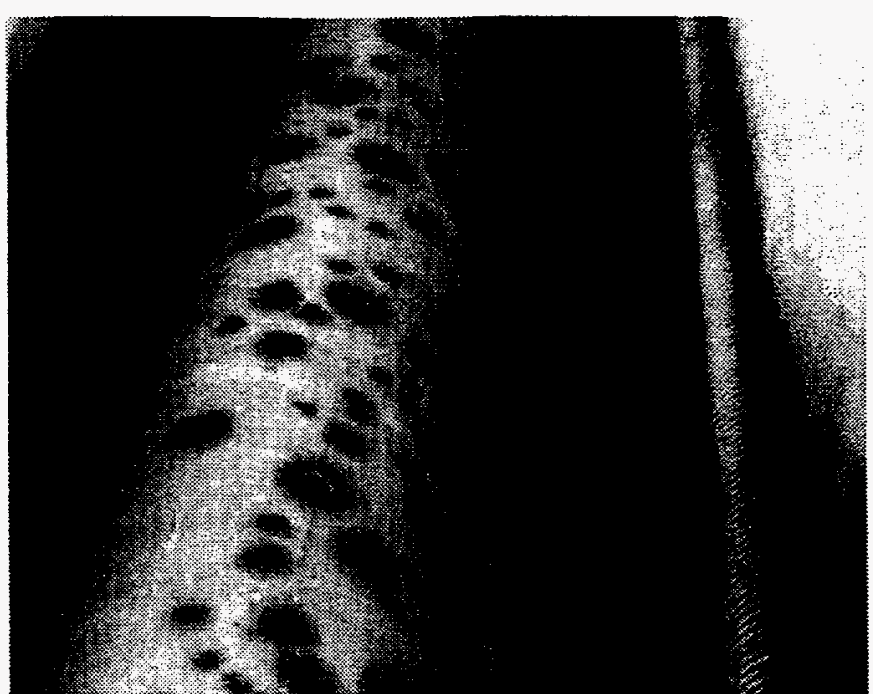

Figure 4: HV damage to G-11 tube.

electrical breakdown at $15 \mathrm{kV} \mathrm{DC}$, while the green tubing survived testing to $85 \mathrm{kV} \mathrm{DC}$. Only two tan-colored tubes were used in the load assembly. One of these, positioned such that it was subjected to the second-highest electrical potential in the pressure vessel, showed significant stress (see Fig. 4). The other tan tube, located farther down the resistor string where the electrical potential is well reduced, showed no evidence of significant electrical breakdown.

Evidence of excess heat was noted in all of the tubing in

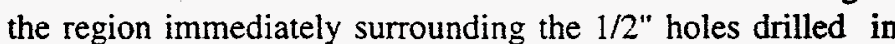
the top of each tube to provide an escape path for hot water within the tube. It is believed that the $1 / 2$ " holes are too small in diameter to allow the heated water inside the tubing to disperse rapidly into the general water flow, resulting in the discoloration noted (see Fig. 5).

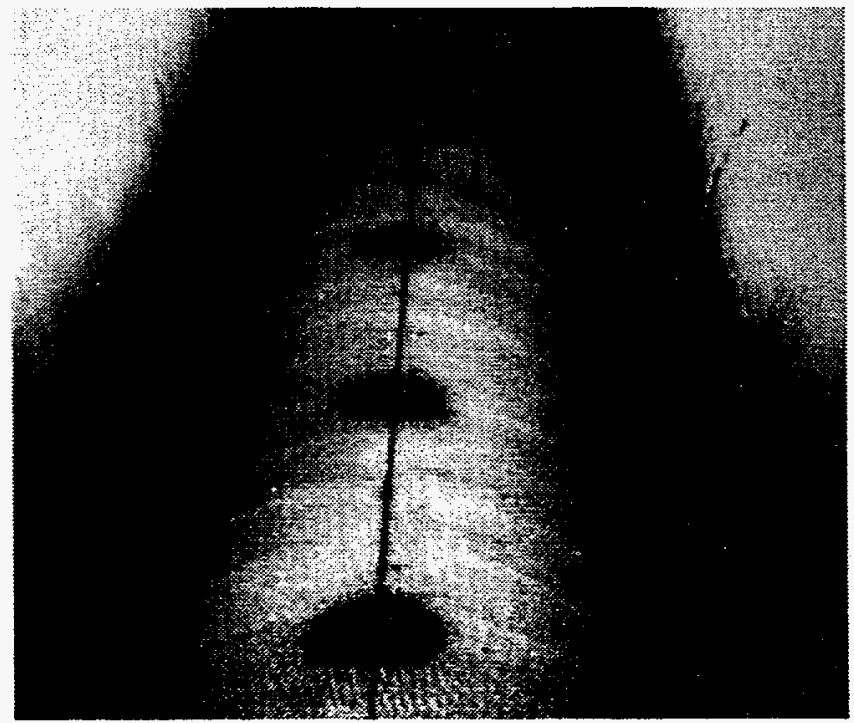

Figure 5: Heat stress on G-11 tubing near $1 / 2$ " diameter holes. 
Corrosion of interior metal components was limited to the wirewound resistor elements themselves, which showed slight development pf iron oxide at the electrical connections. This was later determined to be a non-issue, as the contact resistance of these connections was measured and found to be approximately $0.2 \mathrm{ohms}$ or less. The resistor wire itself showed no evidence of corrosion or degradation, the interior of the pressure vessel showed no signs of electrolytic action between interior metal components, and there was no indication of any electrical arcing to the inside surface of the vessel.

\section{DESIGN CHANGES}

Several design changes have been proposed to enhance the operational convenience of the load system and to correct design problems discovered after inspection of the pressure vessel interior. Permanent installation of the coaxial high-voltage cable and the load system interlock/control cable, complete with connectors located at each power supply location, will make the system much easier to use. Concerning the problems noted in the pressure vessel, the following improvements are planned:

- Replace the resistor elements themselves with continuous nichrome resistor wire material wound around ceramic or G-10 bobbins, thus eliminating many mechanical parts in the resistor assembly and reducing the number of electrical connections necessary in the resistor string. This will allow currently wasted space between the resistors to be used for more resistor materia, increasing the total resistance of the load to approximatly $5,300 \mathrm{ohms}$ and compensating for the leakage current through the cooling water. Water column calculations indicate that the major leakage current path through the cooling water is most likely between the resistor windings themselves, and thus is not indicative of electrolytic actions [2]. Therefore, it is felt that this leakage current can be safely included as a component of the load current.

- Upgrade all G-11 material inside the pressure vessel to material which can withstand electrical breakdown to 85 kV DC.
- Enlarge the hot-water escape holes on the top of all resistor tubes to one inch diameter, easing the escape of heated water from the interior of the tubes.

- Design and install a spring-loaded pressure contact between the input cable well and the series-resistor string, thereby eliminating the "flying lead" connection presently used.

- Install a filter (10 to 20 metal mesh is adequate) near the vessel water inlet to prevent particulate matter from accumulating inside the pressure vessel. The deionized water for the vessel is filtered only near the pump. However, in the $150 \mathrm{ft}$ of piping from the pump to the vessel a lot of contamination can occur, especially if there is other piping work being performed in the same area.

- Install a satellite polishing bed of deionizing canisters be installed in the supply piping to the pressure vessel to keep the resistivity of the cooling water at a predetermined minimum.

- Coat the interior of the pressure vessel with an epoxy resin to reduce the effects of stray leakage current to the vessel interior.

\section{SUMMARY}

It is planned to use this water-cooled high-voltage load system to support future maintenance, performance testing, and troubleshooting of the APS if power supplies. The proposed design improvements are scheduled to be completed by the end of 1995 and should significantly improve the convenience, performance, and reliability of the load system. It will remain permanently installed in the APS rf klystron gallery as part of the rf system.

\section{REFERENCES}

[1] Thomson TH2089A Klystron Amplifier Operating Manual, UTH 2089, November, 1986.

[2] D. Horan, R. Kustom, M. Ferguson, "Design and Performance of a 2-Megawatt High Voltage DC Test Load," Proc. of the 1994 European Particle Accelerator Conference, Vol. 3, pp. 1936-1938 (1994).

\section{DISCLAIMER}

This report was prepared as an account of work sponsored by an agency of the United States Government. Neither the United States Government nor any agency thereof, nor any of their employees, makes any warranty, express or implied, or assumes any legal liability or responsibility for the accuracy, completeness, or usefulness of any information, apparatus, product, or process disclosed, or represents that its use would not infringe privately owned rights. Reference herein to any specific commercial product, process, or service by trade name, trademark, manufacturer, or otherwise does not necessarily constitute or imply its endorsement, recommendation, or favoring by the United States Government or any agency thereof. The views and opinions of authors expressed herein do not necessarily state or reflect those of the United States Government or any agency thereof. 